\title{
Case Report of Management Problem of Juvenile Myoclonic Epilepsy
}

\author{
Ivan P. Artyukhov, Olga S. Shilkina, Natalia A. Shnayder*, Diana V. Dmitrenko, \\ Elena N. Bochanova, Evgeniya A. Shapovalova, Irina G. Strotskaya \\ The Voyno-Yasenetsky Krasnoyarsk State Medical University of the Health Ministry of Russia, The University \\ Clinic, Krasnoyarsk, Russia \\ Email: "nataliashnayder@gmail.com
}

Received 19 May 2016; accepted 4 July 2016; published 7 July 2016

Copyright (C) 2016 by authors and Scientific Research Publishing Inc.

This work is licensed under the Creative Commons Attribution International License (CC BY). http://creativecommons.org/licenses/by/4.0/

c. (i) Open Access

\begin{abstract}
Juvenile myoclonic epilepsy (JME) is one of the most common types of idiopathic generalised epilepsy. It starts in teenage years, yet it is frequently misdiagnosed or diagnosed very late, thereby resulting in inadequate therapy plan and worsening of symptoms. Timely diagnosis of JME is crucial for the correct management of symptoms and prevention of disease development. In this case report we describe a case of a 33-year-old woman who did not receive appropriate care due to a late diagnosis of her JME condition.
\end{abstract}

\section{Keywords}

Idiopathic Generalised Epilepsy, Juvenile Myoclonic Epilepsy, Clinic, Management, Delayed Diagnosis, Prognosis

\section{Introduction}

Juvenile myoclonic epilepsy (JME) is a subtype of idiopathic generalized epilepsy, comprising 5\% - 10\% of all forms of epilepsy and $27 \%$ of idiopathic types [1] [2]. The incidence of JME in the general population is estimated to be 1 case per 1000 - 2000 people internationally. However, the exact figures may be higher, as the condition is often misdiagnosed [3].

JME is characterised by myoclonia during awakening, generalised tonic-clonic seizures, typical absences and usually presents for the first time in adolescence [4]. Typically, the first seizure type to present is absence seizures - these start anywhere between the ages of 5 and 16 years of age. Myoclonic jerks are seen about 1 to 9 years later, with an average age of 14 or 15 years. Generalized tonic-clonic seizures appear a few months later

${ }^{*}$ Corresponding author.

How to cite this paper: Artyukhov, I.P., Shilkina, O.S., Shnayder, N.A., Dmitrenko, D.V., Bochanova, E.N., Shapovalova, E.A. and Strotskaya, I.G. (2016) Case Report of Management Problem of Juvenile Myoclonic Epilepsy. Case Reports in Clinical Medicine, 5, 217-224. http://dx.doi.org/10.4236/crcm.2016.57040 
after that, although they can appear earlier [5]. Findings from some studies suggest that JME is slightly more prevalent among females than males. The reason is unknown. However, data from other studies indicate similar prevalence in both sexes [6].

Diagnosis is typically made based on patient history. The physical examination should be normal. The electroencephalography (EEG) is the most important test in making a diagnosis of JME. The EEG in untreated individuals is typically abnormal with what is known as a 3 - $6 \mathrm{~Hz}$ generalized polyspike and wave discharge [7]; $30 \%$ of patients may show a photoparoxysmal response or an abnormal EEG in response to flickering lights [8]. Magnetic resonance imaging (MRI) is typically normal. Some patients with brain MRIs, particularly if the MRIs are high-definition (or high-Tesla) studies, have shown minor abnormalities of cortical development [9] [10].

Timely diagnosis of JME is crucial for the correct management of symptoms and prevention of disease development [11]. In general, excellent seizure control can be achieved in JME patients with relatively low doses of appropriate anticonvulsants (e.g., valproic acid) [12]. Women are often started on alternative medications due to valproic acid's high incidence of fetal malformations [13] [14]. Lamotrigine, levetiracetam, topiramate, and zonisamide are alternative anti-epileptic medications with less frequent incidence of pregnancy related complications, and they are often used first in females of childbearing age. Carbamasepine may aggravate primary generalized seizure disorders such as JME. Treatment is lifelong. Patients should be warned to avoid sleep deprivation. The risk of recurrence is higher than $80 \%$ if anticonvulsants are withdrawn; hence, lifelong treatment is usually necessary.

Prognosis is often included as part of a syndromic complex, but the long-term course of JME has never been very clear. With due respect to the Revised Terminology creators, the name JME contributes to a confounded perception of its prognosis. The term "juvenile" refers to the age of onset, but for many patients, families, and even practitioners, the term implies that as the patient matures, the syndrome will resolve. JME is not a pediatric epilepsy syndrome likely to remit with the passing of adolescence, but this is belied by its very nomenclature [15] [16].

However, often the diagnosis is established late, when disease had progressed or suboptimal treatments were prescribed. Consequently, seizures may aggravate and side effects from ineffective treatments could reduce the quality of life of JME patients. We have previously proposed various improvements for diagnosis of JME. In this report we present a case of a 33-year-old woman, who was diagnosed with JME late in the disease establishment, and how subsequent changes in her treatment plan improved her symptoms and quality of life.

\section{Case Report}

A 33-year-old woman was referred to the Neurological Centre of Epileptology, Neurogenetics and Brain Research of the University Clinic for the first time in October 2015. She complained about episodes of short-term loss of consciousness without falling, with termination of started action and with post-episode confusion. Frequency of the documented episodes was up do daily. She also described very rare (once a year) episodes with falls and generalised muscle spasms, as well as muscle twitching in the superficial sleep stages. Finally, she reported pains in the frontal lobe and between the eyes, sometimes of high intensity, which could be interrupted with dehydration therapy (oral glycerol solution).

The patient's anamnesis revealed that at the age of 8 , she suffered a trauma of the frontal bones, with breaks around the nose area, as a result of a swing blow, which was treated conservatively. Approximately 6 months post-incident, absences presented, which at the time were linked to her frontal bone trauma by her general practitioner (GP). The frequency of these absences was very high, up to 40 times a day, though to retrospectively confirm true reason of these episodes is not possible (video-EEG monitoring was not performed). Absences grew more frequent after sleep deprivation and with stress.

At the age of 18, after a stress-inducing situation, generalised tonic-clonic seizures appeared, which happened predominantly in the early hours at home, and less frequently at work, in the first half of the day.

The disease subsequently progressed due to inadequate pharmacotherapy. The patient received barbiturates, carbamazepine and acetazolamide. There was also an attempt to introduce valproate (Depakine) without control of valproic acid levels in the blood, but without any registered clinical effect. The last course of barbiturate (Benzonal) was prescribed 2.5 years ago and no further anti-epileptic therapy was administered. Approximately 6 months ago, myoclonic seizures during superficial sleep stages presented in addition to the other symptoms.

Despite progressive disease and inadequate treatment plan, the patient successfully completed her third-level 
degree in economics and worked her way up to a senior management role. Her current status is unemployed, she is married and has a daughter aged 12. Pregnancy age was 21 years old and no generalised tonic-clonic seizures were observed for the duration of pregnancy, though absences remained. Lactation continued for 6 months post-birth and no generalised tonic-clonic seizures were observed during that period.

MRIs of the brain in 2008 and 2010 were normal, but revealed signs of chronic mild sinusitis, though the patient is currently not registered with an ENT doctor.

In 2015 the patient underwent routine EEG within a health service initiative, and at frequency of $16 \mathrm{~Hz}$, photosensitive typical absence was registered, up to several minutes. The patient was referred to a specialised consultant neurologist-epileptologist due to futility of the previous treatment plans prescribed elsewhere.

Following the consultation, the patient was deemed adequate and critical intellect corresponded to her age and education level. The general mood was balanced, with slight elevation of situational anxiety. Skin was clear, lymph nodes were not palpable and cranial nerves were intact. No sensitivity disorders, meningeal signs or pelvic problems were observed.

The initial diagnosis was idiopathic generalised epilepsy: JME with typical myoclonic absences, including photosensitive, rare generalised tonic-clonic seizures and uncompensated myoclonia of limbs in the superficial sleep stages. Concomitant diseases included chronic facial pains (prosopalgia) based on recurrent chronic sinusitis resulting from a trauma of the facial bones of the skull in the past.

Further additional tests were:

As a result of the recommended additional tests, video-EEG monitoring $(3 \mathrm{~h})$ registered a pattern of frequent typical absences of high intensity (Figure 1), with a tendency to escalate in frequency and power under hypoxia and during sleep. Average frequency of absences during 24 hours was over 150, which demanded an immediate administration of antiepileptic drugs.

Depakene chronosphere dose scheduling was initiated as follows:

Week 1: $\quad 100 \mathrm{mg}$ in the morning $+100 \mathrm{mg}$ in the evening

Week 2: $\quad 100 \mathrm{mg}$ in the morning $+200 \mathrm{mg}$ in the evening

Week 3: $\quad 200 \mathrm{mg}$ in the morning $+200 \mathrm{mg}$ in the evening

Week 4 onwards: $200 \mathrm{mg}$ in the morning $+300 \mathrm{mg}$ in the evening regularly. Morning-evening interval was 12 hours minimum.

Repeat observation of the woman in December 2015 revealed an improvement in disease symptoms. Episodes with loss of consciousness ceased, memory and mental activity improved, as well as overall health, mood and general wellbeing. It is noteworthy that the patient reported improvements in family relationships, where previously she found it challenging to communicate effectively with her husband and daughter. Video-EEG monitoring (3 h) no registered a pattern of typical absences and photosensitivity response (Figure 2). Therapeutic drug monitoring showed normal level valproic acid in serum- $63 \mu \mathrm{g} / \mathrm{mL}$ (the recommended range for the treatment of epilepsy is $50-100 \mu \mathrm{g} / \mathrm{mL}$ total valproic acid). The dosage was optimal for her, because the valproic acid level was within the therapeutic range and the patient was receiving treatment benefits (e.g., suppression of seizures or mood swings) without adverse effects [17] [18].

\section{Discussion}

In 1822, "myoclonus" was described as "a symptom associated with epilepsy" by Pritchard [19]. Delasiave in 1854 termed it "petit mal moteur". In 1867, Herpin gave the first detailed description of a patient with juvenile myoclonic epilepsy (JME) calling the myoclonic jerks “secousses". In 1881, Gowers classified the jerks among the generalised "auras" and considered them to be epileptic. Unvericht described progressive myoclonic epilepsy in 1901 but failed to recognise the existence of more benign variants. In 1957, Janz and Christian published their article on 47 patients with "impulsive petit mal". Lund in 1975 introduced the term JME and this term was soon admitted into the international classification system thereafter. Until now, JME continues to be under-appreciated and under-diagnosed. Accurate diagnosis is important as it usually responds well to treatment with appropriate anticonvulsants and misdiagnosis often results in unnecessary morbidity. In addition lifelong therapy is usually indicated as the natural history is one of relapse off treatment, even after a prolonged seizure-free period [20].

Many clinicians believe that in the presence of an adequate supportive history, EEG abnormalities, normal intelligence, and normal neurologic findings, neuroimaging studies are unnecessary. Typical electroencephalo- 


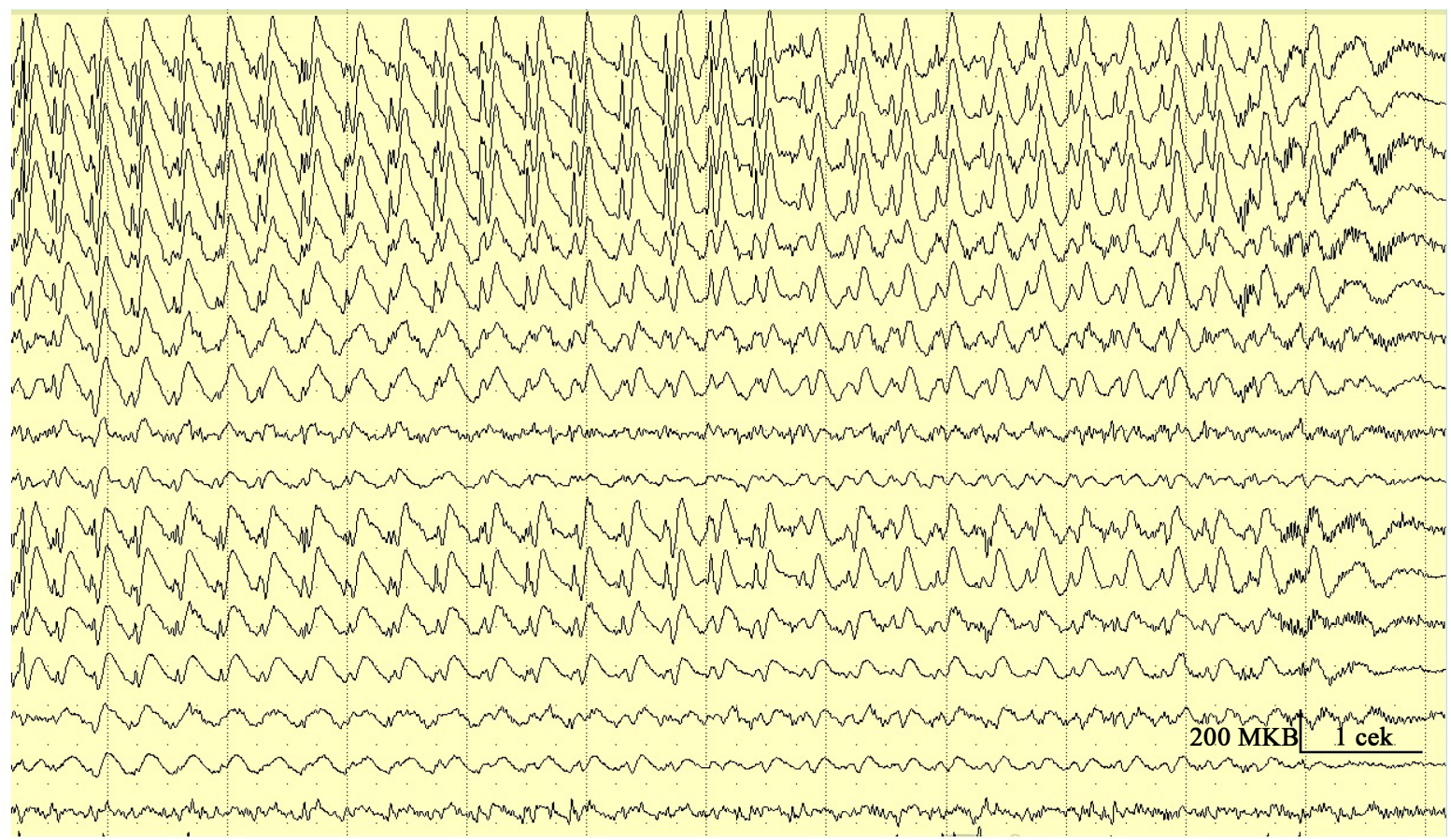

(a)

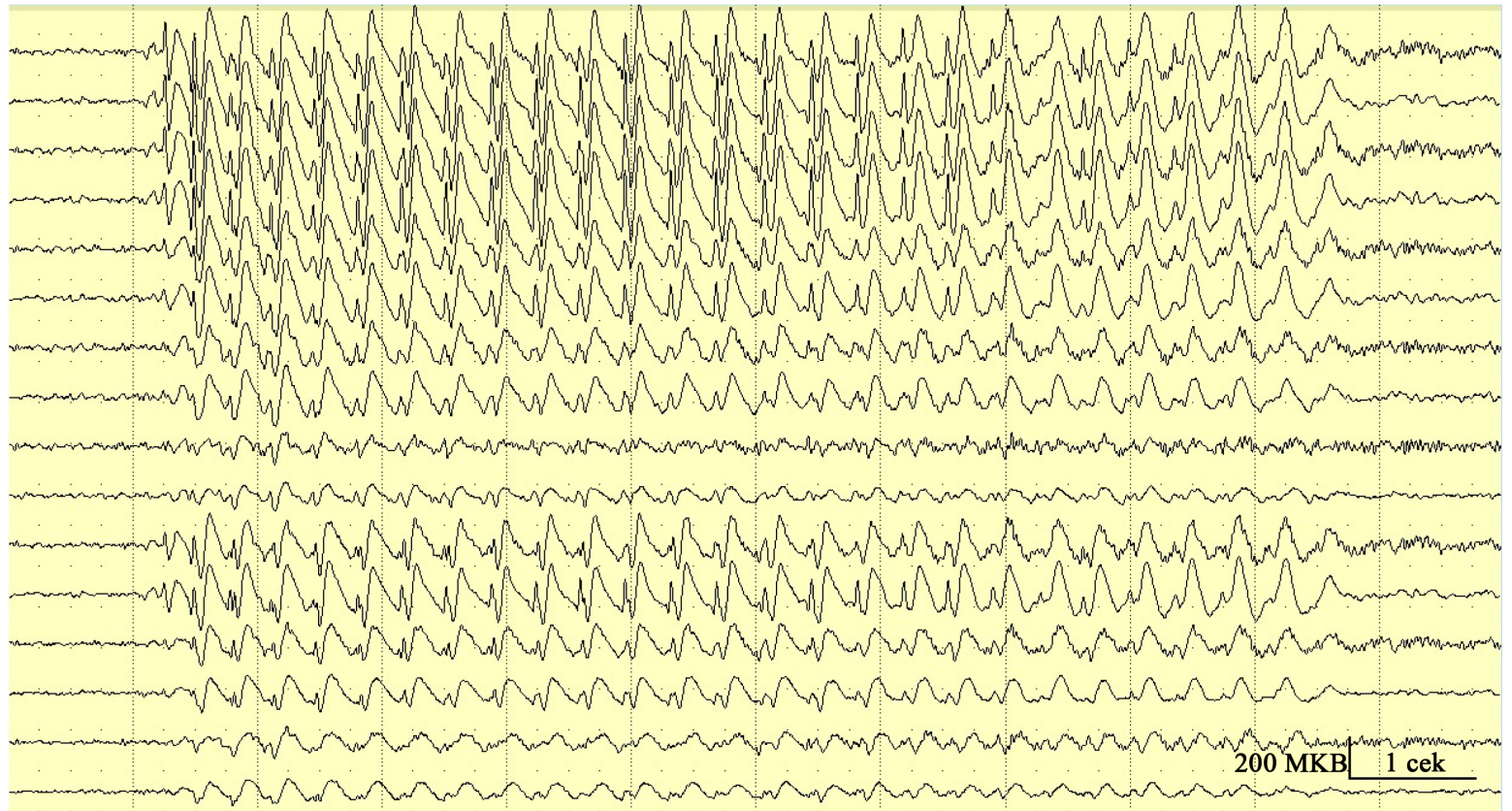

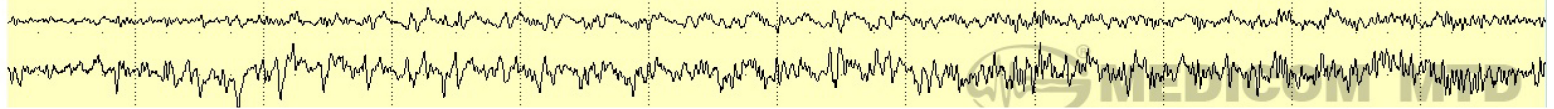

(b)

Figure 1. Video-EEG monitoring before correction of JME treatment (visit 1): the typical EEG abnormality consists of a generalized 3- to 4-Hz double spike (a) or spike (b) and slow-wave discharges lasting 12 (a) and 10 seconds (b). Amplitude of paroxysmal activity $-200-270 \mu \mathrm{V}$.

graphic abnormalities are highly supportive of the clinical diagnosis of JME. However, the clinical scenario might not be as clear as the classical description would suggest. As this case report demonstrates, delayed diagnosis 


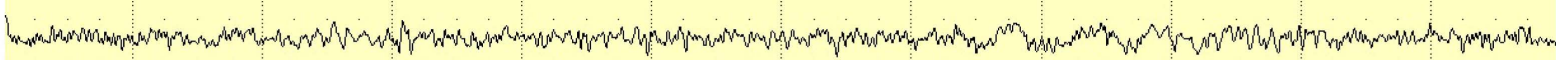

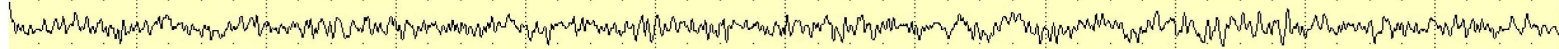

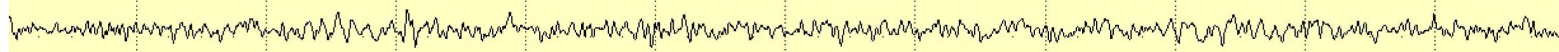

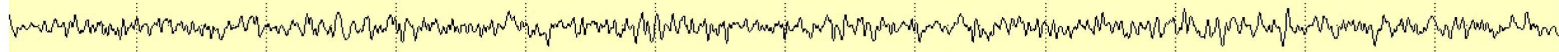

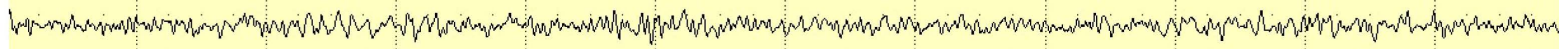

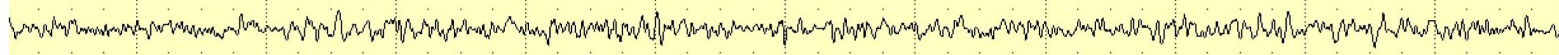

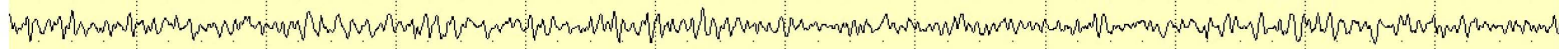

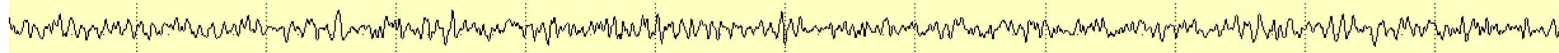

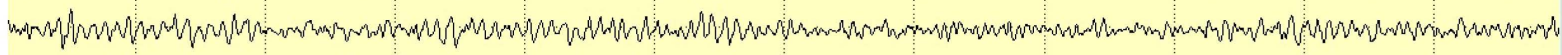

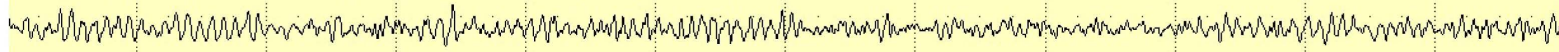

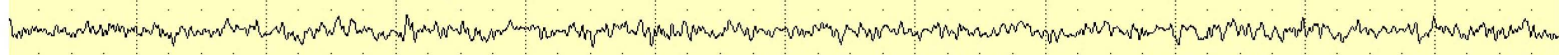

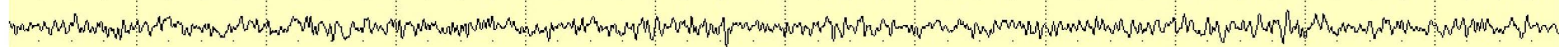

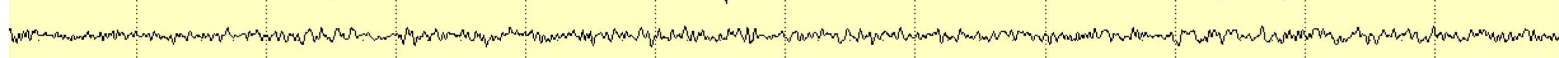

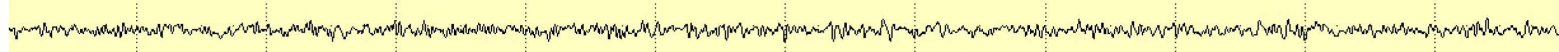

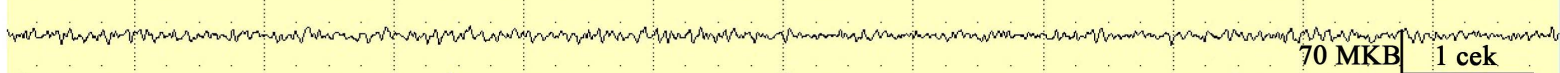

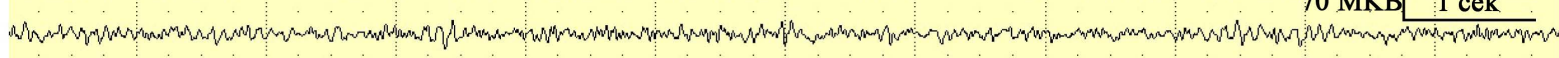

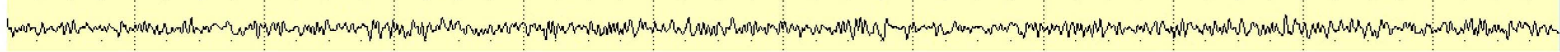

(a)

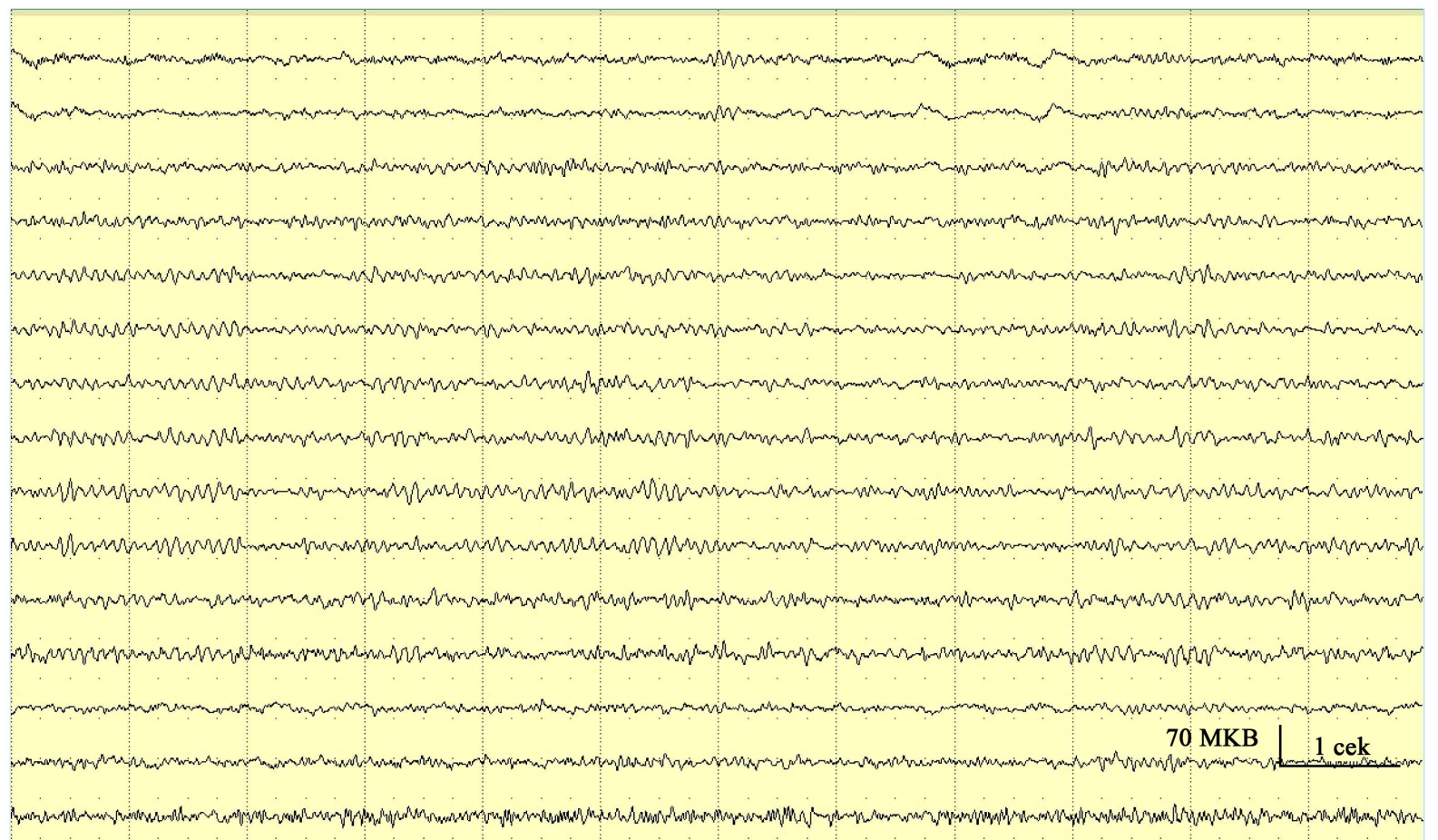

(b)

Figure 2. Video-EEG monitoring after correction of JME treatment (visit 2): no any epileptiformicinterictal EEG abnormality (a) (b). Amplitude of normal brain activity $-35-50 \mu \mathrm{V}$.

(and/or misdiagnosis) of JME directly impacts development of the disease. Inadequate treatment allows aggravation of seizures and worsening of the condition, alongside undesired side effects and emotional stress, all of which significantly reduce patients' quality of life. Such mistakes in diagnosis are common and widespread not 
only in the Siberian Federal Region in Russian Federation, but also in other countries [11] [21]. It is essential that patient's anamnesis is thorough and detailed. This can be facilitated by active questioning about presence of myoclonic seizures in patients, who may be ignoring (or not remembering) these episodes, especially at first presence. In addition, family members, friends, classmates and teachers could be quizzed to get a more complete picture of the disease. Awareness should be raised among GPs to flag such conditions and thoroughly investigate causes of seizures.

It is important to keep in mind the possibility of childhood or juvenile absence epilepsy transformation into JME in young patients to maximise a timely and correct diagnosis [6]. Catching JME early will enable correct management of the disease and subsequent long-term improvement in quality of life.

The selection of antiepileptic drugs for the treatment of JME depends on several factors, including the patient's comorbidities, preferences, previous history of adverse events, gender and pharmacogenetics [17]. In most patients with JME, seizures are well controlled with monotherapy. Valproic acid has been considered the treatment of choice for JME for many years, but epileptologists are increasingly using other choices as first-line therapies. Approximately $80 \%$ of patients with JME become seizure free with valproate monotherapy. Also, other antiepileptic medications including levetiracetam (LEV), lamotrigine (LTG), topiramate (TPM) and zonisamide (ZNS) may be used as first line or as add-on therapy.

In medical school, physicians are taught to treat patients and not serum concentrations. A low-dose requirement is not unusual; in fact, the great majority of patients with JME need relatively low levels of anticonvulsants to achieve adequate seizure control (as long as it is an appropriate medication for the syndrome) [22].

Precipitating factors for seizures should be avoided. These include avoiding moderate to heavy consumption of alcohol, fatigue, and photosensitising lights. Patients should be encouraged to develop regular sleeping habits. Advice regarding driving restrictions, working at height, and supervised swimming is appropriate. During pregnancy, the risks of discontinuing treatment outweigh the benefits. The importance of pre-pregnancy counselling and the addition of folic acid is an essential part of management in women of childbearing potential [20]. A great majority of children born to women taking anticonvulsant monotherapy are healthy. Valproic acid and divalproex sodium clearly pose a recognized risk of neural-tube defects (category D) that is higher than the risk associated with older anticonvulsants. Evidence suggests that supplementation with folic acid may decrease this risk [14] [18] [22].

In general, low doses of appropriate anticonvulsants are needed to successfully treat JME. The goal of pharmacological management is to render the individual seizure-free without side effects of the medication. Treatment with phenytoin, carbamazepine, or phenobarbital may control some seizure components of JME (typically at high doses), but these drugs may increase seizure frequency (e.g., myoclonic exacerbation with carbamazepine) and occasionally precipitate new seizure types, such as absence seizures [22]. Treatment with lacosamide may be effective in the treatment of JME, larger studies are needed to explore efficacy and role of lacosamide in the treatment of this disorder [23]. About $80 \%-90 \%$ of patients with JME respond to appropriate antiepileptic treatment and achieve seizure freedom,and about $15 \%$ of patients become intractable.The predictors of pharmacoresistance include 1) the coexistence of all three seizure types (myoclonic jerks, absence seizures, and GTCS) and 2) the existence of associated psychiatric problems [24].

\section{Conclusions}

A 33-year-old woman, having a disease onset at the age of 8, was first surveyed in special Neurological Center and JME was diagnosed. Administration of non-recommended drugs in the treatment of the disease significantly reduced the patient's quality of life and as a result of correct diagnosis and appropriate treatment of the disease the patient's condition and her quality of life have stabilized.

Although JME has been described as a benign condition, it should be borne in mind that any condition that places the patient at risk for GTCS increases morbidity and mortality. Failure to diagnose the condition increases the patient's morbidity. All patients require lifelong treatment. As mentioned, patients with JME are at increased risk of relapse if treatment is discontinued [20].

\section{Informed Consents}

Informed consent was obtained from the patient. 


\section{Conflict of Interest}

The authors state that they have no Conflict of Interest (COI).

\section{References}

[1] Sullivan, J.E. and Dlugos, D.J. (2004) Idiopathic Generalized Epilepsy. Current Treatment Options in Neurology, 6, 231-242. http://dx.doi.org/10.1007/s11940-004-0015-6

[2] Shnayder, N.A., Dmitrenko, D.V., Sadykova, A.V., et al. (2011) Epidemiological Studies on Epilepsy in Siberia. Medical and Health Science Journal, 6, 35-42. http://dx.doi.org/10.15208/mhsj.2010.105

[3] Camfield, C.S. and Camfield, P.R. (2009) Juvenile Myoclonic Epilepsy 25 Years after Seizure Onset: A Population-Based Study. Neurology, 73, 1041-1045. http://dx.doi.org/10.1212/WNL.0b013e3181b9c86f

[4] Wolf, P., Yacubian, E.M., Avanzini, G., et al. (2015) Juvenile Myoclonic Epilepsy: A System Disorder of the Brain. Epilepsy Research, 114, 2-12. http://dx.doi.org/10.1016/j.eplepsyres.2015.04.008

[5] Janz, D. (1985) Epilepsy with Impulsive Petit Mal (Juvenile Myoclonic Epilepsy). Acta Neurologica Scandinavica, 72, 339-359. http://dx.doi.org/10.1111/j.1600-0404.1985.tb00900.x

[6] Shilkina, O., Petrov, K., Diuzhakova, A., Marueva, N. and Shnayder, N. (2016) Frequency of Juvenile Myoclonic Epilepsy Clinical Phenotypes in Siberia. World Journal of Neuroscience, 6, 32-36. http://dx.doi.org/10.4236/wjns.2016.61004

[7] Sadleir, L.G., Scheffer, I.E., Smith, S., et al. (2009) EEG Features of Absence Seizures in Idiopathic Generalized Epilepsy: Impact of Syndrome, Age, and State. Epilepsia, 50, 1572-1578. http://dx.doi.org/10.1111/j.1528-1167.2008.02001.x

[8] Lu, Y., Waltz, S., Stenzel, K., et al. (2008) Photosensitivity in Epileptic Syndromes of Childhood and Adolescence. Epileptic Disorders, 10, 136-143.

[9] Tae, W.S., Kim, S.N., Joo, E.Y., et al. (2008) Cortical Thickness Abnormality in Juvenile Myoclonic Epilepsy. Journal of Neurology, 255, 561-566. http://dx.doi.org/10.1007/s00415-008-0745-6

[10] Roebling, R., Scheerer, N., Uttner, I., et al. (2009) Evaluation of Cognition, Structural, and Functional MRI in Juvenile Myoclonic Epilepsy. Epilepsia, 50, 2456-2465. http://dx.doi.org/10.1111/j.1528-1167.2009.02127.x

[11] Panayiotopoulos, C.P., Tahan, R. and Obeid, T. (1991) Juvenile Myoclonic Epilepsy: Factors of Errors Involved in the Diagnosis and Treatment. Epilepsia, 32, 672-676. http://dx.doi.org/10.1111/j.1528-1157.1991.tb04708.x

[12] Wheless, J.W., Clarke, D.F., Arzimanoglou, A. and Carpenter, D. (2007) Treatment of Pediatric Epilepsy: European Expert Opinion, 2007. Epileptic Disorders, 9, 353-412.

[13] Fatemeh, M. and Nazanin, E. (2012) Pregnancy Complications and Outcomes in Women with Epilepsy. Open Journal of Obstetrics and Gynecology, 2, 230-234. http://dx.doi.org/10.4236/ojog.2012.23047

[14] Dmitrenko, D.V., Shnayder, N.A., Kiselev, I.A., et al. (2014) Problems of Rational Therapy for Epilepsy during Pregnancy. Open Journal of Obstetrics and Gynecology, 4, 506-515. http://dx.doi.org/10.4236/ojog.2014.49072

[15] Senf, P., Schmitz, B., Holtkamp, M. and Janz, D. (2013) Prognosis of Juvenile Myoclonic Epilepsy 45 Years after Onset: Seizure Outcome and Predictors. Neurology, 81, 2128-2133. http://dx.doi.org/10.1212/01.wnl.0000437303.36064.f8

[16] Harden, C. (2014) Juvenile Myoclonic Epilepsy-What Does the Future Look Like? Epilepsy Currents, 14, $150-151$. http://dx.doi.org/10.5698/1535-7597-14.3.150

[17] Shnayder, N., Pilugina, M., Dmitrenko, D., et al. (2011) Pharmacogenetics of Valproic Acid as Unmodified Risk Factor of Adverse Drug Reactions. Medical and Health Science Journal, 7, 26-38. http://dx.doi.org/10.15208/mhsj.2011.129

[18] Shnaider, N.A., Sychev, D.A., Pilyugina, M.S., Dmitrenko, D.V., Bochanova, E.N. and Shapovalova, E.A. (2012) Importance of the Pharmacokinetics of Valproic Acid in an Individualized Approach to the Treatment of Epileptic Women of Fertile Age. Neuroscience and Behavioral Physiology, 42, 963-968. http://dx.doi.org/10.1007/s11055-012-9663-2

[19] Genton, P. and Gelisse, P. (2001) Juvenile Myoclonic Epilepsy. Archives of Neurology, 58, 1487-1490. http://dx.doi.org/10.1001/archneur.58.9.1487

[20] Renganathan, R. and Delanty, N. (2008) Juvenile Myoclonic Epilepsy: Under-Appreciated and Under-Diagnosed. Postgraduate Medical Journal, 79, 78-80. http://dx.doi.org/10.1136/pmj.79.928.78

[21] Genton, P., Gelisse, P. and Thomas, P. (2000) Juvenile Myoclonic Epilepsy Today: Current Definitions and Limits. In: Schmitz, B. and Sander, T., Eds., Juvenile Myoclonic Epilepsy: The Janz Syndrome, Wrightson Biomedical Publishing, Petersfield, 11-32. 
[22] Carroll, E. and Cavazos, J.E. (2016) Juvenile Myoclonic Epilepsy. Medscape. http://emedicine.medscape.com/article/1185061-overview

[23] Gelisse, P., Genton, P., Thora, P., Rey, M., Samuelian, J.C. and Dravet, C. (2001) Clinical Factors of Drug Resistance in Juvenile Myoclonic Epilepsy. Journal of Neurology, Neurosurgery \& Psychiatry, 70, 240-243. http://dx.doi.org/10.1136/jnnp.70.2.240

[24] Afra, P. and Adamolekun, B. (2012) Lacosamide Treatment of Juvenile Myoclonic Epilepsy. Seizure, 21, $202-204$. http://dx.doi.org/10.1016/j.seizure.2011.12.010

\section{Submit or recommend next manuscript to SCIRP and we will provide best service for you:}

Accepting pre-submission inquiries through Email, Facebook, Linkedin, Twitter, etc A wide selection of journals (inclusive of 9 subjects, more than 200 journals)

Providing a 24-hour high-quality service

User-friendly online submission system

Fair and swift peer-review system

Efficient typesetting and proofreading procedure

Display of the result of downloads and visits, as well as the number of cited articles

Maximum dissemination of your research work

Submit your manuscript at: http://papersubmission.scirp.org/ 